\title{
A Study on Online Education Model using Location Based Adaptive Mobile Learning
}

\author{
K. Krishna Prasad ${ }^{1}$ \& P. S. Aithal ${ }^{2}$ \\ ${ }^{1}$ Research Scholar, Rayalaseema University, Kurnool-518 007, Andra Pradesh, India \\ ${ }^{2}$ Department of Computer Science, Srinivas Institute of Management Studies, Pandeshwar, \\ Mangalore - 575 001, Karnataka, INDIA \\ E-mail: karanikrishna@gmail.com
}

Type of the Paper: Research Paper.

Type of Review: Peer Reviewed.

Indexed In: OpenAIRE.

DOI: http://dx.doi.org/ 10.5281/zenodo.820457.

Google Scholar Citation: IJAEML

\section{How to Cite this Paper:}

Krishna Prasad, K., \& Aithal, P. S. (2017). A Study on Online Education Model using Location Based Adaptive Mobile Learning. International Journal of Applied Engineering and Management Letters (IJAEML), 1(1), 36-44.

DOI: http://dx.doi.org/ 10.5281/zenodo.820457.

International Journal of Applied Engineering and Management Letters (IJAEML)

A Refereed International Journal of Srinivas University, India.

(C) With Authors.

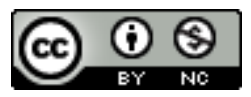

This work is licensed under a Creative Commons Attribution-Non Commercial 4.0 International License subject to proper citation to the publication source of the work.

Disclaimer: The scholarly papers as reviewed and published by the Srinivas Publications (S.P.), India are the views and opinions of their respective authors and are not the views or opinions of the S.P. The S.P. disclaims of any harm or loss caused due to the published content to any party. 


\title{
A Study on Online Education Model using Location Based Adaptive Mobile Learning
}

\author{
K. Krishna Prasad ${ }^{1}$ \& P. S. Aithal ${ }^{2}$ \\ ${ }^{1}$ Research Scholar, Rayalaseema University, Kurnool-518 007, Andra Pradesh, India \\ ${ }^{2}$ Department of Computer Science, Srinivas Institute of Management Studies, Pandeshwar, \\ Mangalore - 575 001, Karnataka, INDIA \\ E-mail: karanikrishna@gmail.com
}

\begin{abstract}
Online educations are gaining more scope due to the busy schedule of working groups and their interest to acquire knowledge in new fields. Working group people find difficult to get admission in top institutions for their interested course due to competition and lack of time flexibility. Regular full-time university affiliated courses become lack of interest for the working group due to outdated curriculum, lack of innovation in teaching, unchanged learning and evaluation environment and lack of industry oriented advanced courses. Some institutions/universities provide short-term online courses for working people, which are liked by many working people due to its new evaluation and learning methods, advanced curriculum and industry oriented subjects. The introduction of mobile wireless communication technology modernization, innovation and globalization are increasingly driving the online education to become ubiquitous, personalized, convenient, and flexible for working groups. In this paper, we discuss based on the location how some short term certification courses can incorporate changes in curriculum. In this paper, we discuss when a particular university introduces some certification courses worldwide, how concepts, regulations or entire subject changes depending on the geographical location. At the time of registration location of the user is accepted from the user. If the registered user changes the location for more than two weeks then that is traced by GPS through the mobile phone and curriculum content changes a little bit. Initially, this is introduced only for some competitive examinations material and short term certification courses related to commerce and political science, which is slightly different depending on the location. This paper discusses how in online short term certification courses, changes in curriculum and innovation in teaching, learning, and evaluation can be implemented for the benefits of working people located in different geographical regions of the world.
\end{abstract}

Keywords: Location Based Learning, GPS, Certification Courses, Wireless Communication Technology.

\section{INTRODUCTION :}

Online educations are learning with the aid of technology without physically visiting institutions or organizations. Technology includes computers, mobile, smartphone and wireless communication devices. The development of internet technology and wireless communication devices made learning ubiquitous. Higher education institutions are adopted virtual learning environment and adopted elearning, through which working people are getting benefited. Learning is a continuous learning process which starts from the birth to death of the human being which helps to develop individual and thereby gaining new knowledge [1]. The traditional education system is static, which means that student is not having the rights to change the content of curriculum or topic of the subject instantaneously and teacher transfers knowledge to students in a confined classroom. Learning with the aid of mobile device or m-learning is not effective or popular due to some constraints, they are: (1) 
small screen size, (2) lack of quality in teaching content, (3) reduced bandwidth, (4) high communication cost, (5) substandard format for learning and certificate, (6) lack of technical skills of teachers, (8) lack of integrated space and lack of one to one communication or eye contact [2-4]. Fourth Generation (4G) communication technology is an advanced wireless standard which can overcome some of the constraints of m-learning, which includes improved transfer rate, customized and ubiquitous service, interactive multimedia and broadband and multimedia services with high speed and capacity [5-8]. The advanced smartphone is having high capacity, memory power and speed compare to an earlier mobile phone, which helps to improve online education journey through them.

Location information of the particular user or student helps to improve studying environment of the student and in providing location-relevant current information in the curriculum or on the subject. Location information is used in m-learning users to retrieve user's current location and further process that data to acquire more information near to their current location and to provide add-on information to users [9-10]. Location information can be extracted with the help of GPS system, which comes in almost all smartphones. Location information can be used for the authentication purpose also. Location Authentication mainly involves three components as Proximity component, Authentication Factor Components, and Known Location Components.

This research Paper is divided into seven sections. In the first section, we cover introductions to online education and location information. Section two explains about the related research study. Section three describes problem statement and objectives of the study. The section four covers Model describing location based information for m-learning. Section five describes conceptual design requirements for the model. Section six makes an analysis of location-based adaptive learning using Advantages, Benefits, Constraints, and Disadvantages. Section seven concludes the study.

\section{RELATED RESEARCH :}

A fair number of researchers have been published in the area of m-learning and Location based information. M-learning is a new learning model of e-learning using portability and immediate communication properties of wireless communication device fused with fast internet service with the aid of advanced smartphones [11]. M-learning is a new paradigm of online learning in which interaction between students and teacher improved and accessible at any without any barriers to classroom [12]. Mobile devices together with other wireless communication devices and internet have made the teaching of English language as a second language easy and more attractive [13]. The study reveals that mobile learning helps to improve the performance of students despite their division based on language, religion, class, and community. The experimental study was conducted among the distance learners of Vinayaka Mission University at Salem in India [14]. The virtual classroom can support urgent and timely need of the students and thereby improve learning process effectiveness. The teacher can teach the student, sitting at residence and students located around $1 \mathrm{Km}$ away from the teacher can form an ad hoc network [15]. Processing learner's contextual information through some devices and delivering adaptive and context-aware educational scenario using mobile device becomes vital to achieving adaptive and personalized mobile learning [16]. To adapt, manipulate and display a web-based framework is presented using small handheld devices. Written text files are converted into natural speech files [17].

Context-aware computing application often implemented for mobile devices and most of the applications solely rely on location information as their sensor information. A location based information most common form of context-ware based sensor information [18-19]. Location-based services are mainly classified as location tracking and Location aware [20]. The guide project and cyber guide and most of the other applications use the positive aware approach with the meaning that application's actions are based on its own positions. Locations tracking services are mainly based on safety based used mainly for tracking student or elder person or any missing persons [21-22]. In most of the location-based information, privacy is the one of an essential issue and is often addressed how sensitive information is kept secured in the applications. The major difference between a location- 
based attribute and other attribute is that location information changes continually and is most relevant to mobile computing.

\section{PROBLEM STATEMENT AND OBJECTIVE OF THE STUDY :}

In traditional classroom based learning, in order to change curriculum or syllabus of the particular course, usually, it takes many years even after the particular subject has witnessed drastic changes over the years. Students are not having the flexibility to change the content or decide their curriculum and its always particular course board of study's decision. In contrast to traditional classroom-based teaching, m-learning has the flexibility for students to take the class at anytime from anywhere without physically sitting inside a classroom. Through context and sensor based customized and ubiquitous services, students can get knowledge as per their requirements and they can decide or contribute to the development of the curriculum [1].

Consider an example a material prepared for competitive examination may not fit well for all places. Generally, a competitive exam consists of different areas as Quantitative Aptitude, Logical Reasoning, and English comprehension, Computer Knowledge and General Awareness and General Knowledge. In this, General Awareness and General Knowledge covers wide areas and it varies from state to state or province. So an organization or institution cannot develop a material that is useable in all state level government competitive examinations. Consider another example where some professional certificate courses related to political science, income tax related subject, law-related subjects having different rules or conditions or changes with respect to States or province of a country.

The aim of this paper is to include location information in m-learning, which will be helpful for students of different regions to avail good dynamic updated content for some competitive examination preparing material and continuously changing topics with respect to place. The central objectives of the study are as follows:

- To study a conceptual model for location-based information for m-learning using GPS.

- To analyze the model with its Advantages, Benefits, Constraints, and Disadvantages

\section{LOCATION BASED ADAPTIVE MOBILE LEARNING -SYSTEM CONFIGURATION :}

Location information of the user is highly important data in Location Based Adaptive Mobile Learning (LBAML). This can be one of the key attributes to change the content of a material or to add more information to the already existing content. In this model, we will be using GPS device, especially GPS receiver to track the geographical position of the user and to provide content based on this data. The task of the GPS receiver is to track latitude, longitude and altitude coordinates of the user, who is trying to access the content of the respective material [23-25]. Once the location sent by the particular user is processed by the server, he will be able to access modified content of the material from geographically dispersed locations. One user can select more than one location at the time of registration. In registration process the user has to register location information along with his/her personal information. The user gets access to material after evaluating User-id, password and location information. The important information about the user like username, password, location information and other personal information's are stored in a cloud database. The diagram of the LBAML architecture is shown in Figure 1. The system has four components as Server, Client (Learner), Location Tracking System and Content Provider Engine. Each component has different functions.

\section{A. Server}

The Server provides permission or privilege to particular subject material like general awareness and general knowledge of competitive examination material to upload the material content SMS and send an announcement to all registered user using WiMax. Following are some important functions of Server component.

- Administrate and maintain all the system tasks.

- Approve the registration request made by the user. Registration details are stored in user profile cloud database. 
- When a new material or some video clip file is uploaded, send SMS to all registered learner who is interested in that respective field.

- Initially, when a request comes from learner send a request to Location Tracking system to know the location of the user.

- Get the response from Location Tracking system and provide access to material based on the location based information.

- After knowing the location of the user, request content provider engine to provide new content based on location information.

- Loads the content or material retrieved by the content provider engine to its database for future processing of client request after evaluating location credentials.

B. Client (Learner)

This component is related to the registered learners who have privileges to use the LBAML system. The learner can connect to the server in order to access content or material of the particular subject. Following are some important function of client component.

- Once the registration is approved by the server, the learner can log in to LBAML system with a valid username, password, and location information.

- Receive SMS from the server stating that new video clip or new information of particular content is uploaded.

- User can change password if required

- The learner can give feedback to the content or material through the server.

- The user can select more than one location at the time of registration.

\section{Location Tracking System}

The location Tracking System helps in finding the location of the registered user. Location Tracking System main component is Global Position System (GPS). GPS receiver keeps track location of the user. Location Tracking System uses Google Maps database to find locations details. Following are some important function of Location Tracking System.

- Identify the learner's location so that location-specific content or material is provided to the user.

- GPS receiver keeps track latitude, longitude and altitude coordinates of the users, who are trying to access the content of the respective material.

- GPS Receiver keeps track of time stamp and date stamp in order to know when the user was at which location and time. For this Location Tracking system uses telecommunication system time in order to maintain standard time.

- If the registered user changes the location for more than two weeks then that is traced by GPS receiver through the mobile phone and curriculum content changes according to a specific location.

\section{Content Provider Engine}

Content Provider Engine acts as a bridge between Location Tracking System and cloud database. When the server is not able to find content or material file requested by the client, the server passes this request to Content Provider Engine. Content Provider Engine searches for the file in cloud database and finds the file. The new file is stored in the local database so that when user requests for the same file, server process the request by retrieving the file from its database. Following are some important function of content provider engine component.

- Successfully search the content or material from the cloud database, when the server is not able to locate or find the requested file.

- Helps to store the new content in server-local database for the future reference

- Provide the content in unique standard version or format.

- Assists for the smooth functioning of LBAML system. 


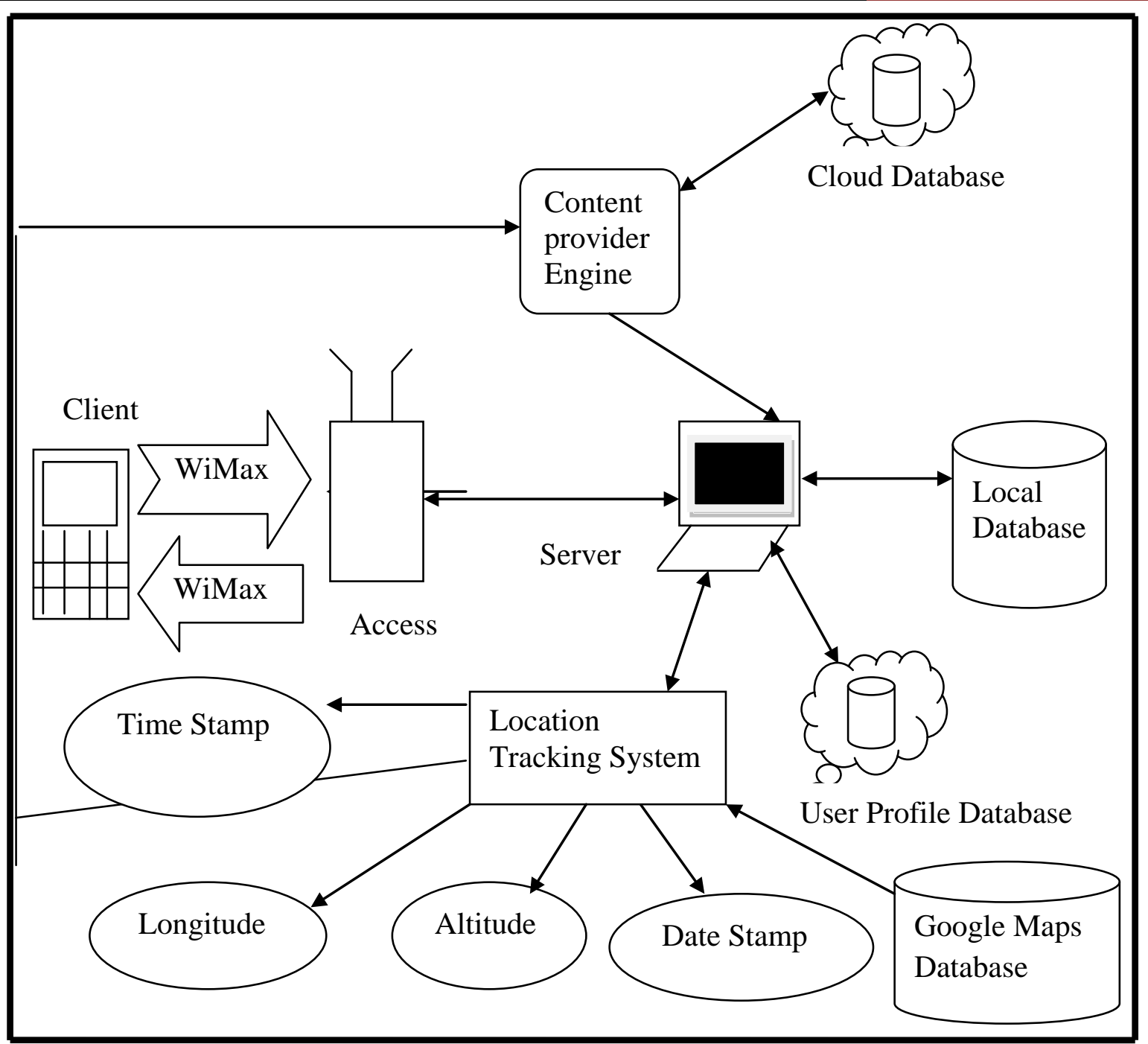

Figure 1: LBAML-System Architecture

\section{DESIGN OF THE SYSTEM :}

The server side component code (desktop application) was designed and implemented using

- NetBeans IDE 8.0.2 J2SE (Java 2 Standard Edition) i.e. based on Java Programming. The client side component code (mobile application) was designed and implemented using

- NetBeans IDE 8.0.2 J2SE (Java 2 Micro Edition) i.e. based on Java Programming. The user profile database cloud database, server database and Content Provider Cloud database tables and DML queries are designed and implemented using

- MySql Server 5.6 .Wireless communication and network was designed and implemented using Standard of 4G communication technology

- WiMax

- HC-SDMA (High Capacity Spatial Division Multiple Access)

- AMC (Adaptive Modulation and coding) Adaptive Hybrid ARQ (Automatic Repeat Request)

- MIMO-OFDM (Multi in Multi out Orthogonal Frequency Division Multiplexing)

- Open distributed Ad-Hoc Wireless Network Content provider engine was designed and developed using

- NetBeans IDE 8.0.2 J2SE (Java 2 Standard Edition) i.e. based on Java Programming. Location Tracking System was designed and developed using 
- NetBeans IDE 8.0.2 J2SE (Java 2 Standard Edition), based on Java Programming

- GPS satellite.

- GPS Location server using Google Maps Database.

\section{ANALYSIS OF LOCATION BASED ADAPTIVE MOBILE LEARNING MODEL :}

LBAML model can be analyzed using its Advantages, Benefits, Constraints and Disadvantages [2627]. LBAML system mainly consists of four components as Client, Server, Location Tracking System and Content Provider Engine.

\section{Advantages}

- The LBAML system provides content based on Location information.

- Learners can get updated and advanced curriculum.

- Services are not restricted to four walls of classroom, can be accessed ubiquitously.

- One Material can be used for all states or province of a country, with each states added information

- Highly updated informative competitive examination material can be prepared.

- LBAML system is easy to implement through existing smart phones because which is having in built GPS tracking system.

- Learners reading environment information can be observed or noted continuously using GPS system.

- Working people can get information easily without any time restrictions.

- Database services are efficiently used in system by making use of different databases.

- LBAML system provides better network coverage for learners because of 4G Technology.

- Limited information of the normal m-learning system can be made information rich with the

\section{Benefits} help of location based services.

- The LBAML system can be extended to some professional certification program easily which are changes continuously depending on geographical locations

- Students can acquire more knowledge which is updated and relevant to industry requirements.

- Popularity and demand of mobile learning can be improved to great extent.

- Having great ability to acquire new customers because of passionate and dynamic services.

- No time and place restrictions, learners can get services anywhere, anytime.

- Global standard can be maintained in content or material.

- Student Friendly environment

- Student having control over the delivery of content.

- More working people will get benefited.

\section{Constraints}

- Lack of new technology

- Maintaining the large repository of data in database and keeping it updated becomes cumbersome process.

- Difficult to apply for professional regular courses.

- Lack of student and teacher one to one interaction or eye contact.

- Monitoring students or learners becomes tedious task.

- Implementation cost is high.

\section{Disadvantages}

- Smart mobile phones are feature rich, which can distraction for learners sometime.

- In developing countries like India, lack of network connections in remote places can make non availability of learning resources.

- Device computability issue.

- Very few subjects changes based on geographical location. 


\section{CONCLUSION :}

M-learning provides great flexibility and freedom for the learners to lean anytime, anywhere, without any restrictions to physical barrier can be extended based on location based information. The learning utilizes different hardware and software technologies and students or learners having complete control over the time limit of the class. In this study we made a conceptual design to provide content based on location based information. Some competitive examination content, especially general knowledge and general awareness changes from state to state, while conducting examination for state government recruited jobs. If we design one standard material and add more information depending on the state where the learners resides, will be more benefited to students. We made an attempt to design a curriculum for this type of scenario.

The Location Based Adaptive Mobile Learning (LBAML) System consists of mainly four components as Client, Server, Location Tracking System and Content Provider Engine. This system makes uses of four databases as local database, Content Provider Engine cloud database, user profile cloud database and Google Maps Database. This paper discusses how in online short term certification courses, changes in curriculum and innovation in teaching, learning and evaluation can be implemented for the benefits for working people located in different geographical regions of the world.

\section{REFERENCES :}

[1] Krishna Prasad, K., \& Aithal, P. S. (2015). Mobile system for Customized and Ubiquitous Learning by 4G/5G.International Journal of Management, IT and Engineering, 5(7), 63-71.

[2] Hayes, P., Joyce, D., \& Pathak, P. (2004). Ubiquitous learning-an application of mobile technology in education. In Proceedings of world conference on educational multimedia, hypermedia and telecommunications,1811-1816.

[3] Keegan, D. and Univ., F. (2002). (2002). The Future of Learning: From eLearning to mLearning.

[4] Woerner, B., \& Howlader, M. (2001). Research Directions for Fourth Generation Wireless. In Enabling Technologies: Infrastructure for Collaborative Enterprises, 2001. WET ICE 2001. Proceedings of Tenth IEEE International Workshops,60-61.

[5] Krishna Prasad, K., \& Aithal, P. S. (2015). Massive Growth of Banking Technology with the Aid of 5G Technologies. International Journal of Management, IT and Engineering, 5(7), 616-627.

[6] Krishna Prasad, K., \& Aithal, P. S. (2016). The Growth of 4G Technologies in India-Challenges and Opportunities. International Journal of Management, IT and Engineering, 6(1), 543-351.

[7] Krishna Prasad, K., \& Aithal, P. S. (2016). Changing Perspectives of Mobile Information Communication Technologies towards Customized and Secured Services through 5G \& 6G. International Journal of Engineering Research and Modern Education (IJERME), 1(2), 210-224.

[8] Krishna Prasad, K., \& Aithal, P. S. (2016). An Online Comparative Study on 4G Technologies Service Providers in India. International Journal of Advanced Trends in Engineering and Technology (IJATET).1(1), 96-101.

[9] Krishna Prasad, K. and Aithal, P. S. (2017). A Study on Enhancing Mobile Banking Services using Location based Authentication . International Journal of Management, Technology, and Social Sciences (IJMTS), (ISSN 24XX-XXXX), $1(1), \quad 48-60$. DOI:http://doi.org/10.5281/zenodo.583230.

[10] Krishna Prasad, K. (2016). Blog Based Self Verification And Self Development Curriculum Model-A Novel Approach To Student Centric Learning. International journal of Scientific Research and Modern Education, 1(1), 435-441 (June 2016) ISSN-2455 - 5630. 
[11] Chen, G. D., Chang, C. K., \& Wang, C. Y. (2008). Ubiquitous learning website: Scaffold learners by mobile devices with information-aware techniques. Computers \& Education, 50(1), 77-90.

[12] Raborife, M., \& Phasha, N. (2010). Barriers to School-Family Collaboration at a School Located in an Informal Settlement in South Africa. Cypriot Journal of Educational Sciences, 5(2), 84-93.

[13] Ayebinik, M., Puteh, M. (2012). Mobile Learning to Support Teaching English as a Second Language. Journal of Education and Practice. 3(7), 56-62.

[14] Chandran, S. (2010). Sustainable distance education through mobile learning: A case study in multicultural context.

[15] Kalaavathi, B., Madhavi, S., \& Duraiswamy, K. (2009). Virtual Class Room Using Mobile Ad Hoc Networks.

[16] Gomez, S., Zervas, P., Sampson, D. G., \& Fabregat, R. (2012, July). Delivering adaptive and context-aware educational scenarios via mobile devices. In Advanced Learning Technologies (ICALT), 2012 IEEE 12th International Conference,197-201.

[17] Madjarov, I., \& Boucelma, O. (2012, September). XESOP: a content-adaptive m-learning environment. In European Conference on Technology Enhanced Learning, 531-536. Springer Berlin Heidelberg.

[18] Schmidt, A., Beigl, M., \& Gellersen, H. W. (1999). There is more to context than location. Computers \& Graphics, 23(6), 893-901.

[19] Ljungstrand, P. (2001). Context awareness and mobile phones. Personal and Ubiquitous Computing, 5(1), 58-61.

[20] Snekkenes, E. (2001, October). Concepts for personal location privacy policies. In Proceedings of the 3rd ACM conference on Electronic Commerce, 48-57.

[21] Marmasse, N. and Schmandt, C. (2003). Safe \& sound a wireless leash in Proceedings of CHI 2003, extended abstracts, 726- 727.

[22] Barkhuus, L., \& Dey, A. K. (2003, July). Location-Based Services for Mobile Telephony: a Study of Users' Privacy Concerns. 3, 702-712.

[23] Zhang, F., Kondoro, A., \& Muftic, S. (2012, June). Location-based authentication and authorization using smart phones. In Trust, Security and Privacy in Computing and Communications (TrustCom), 2012 IEEE 11th International Conference 1285-1292.

[24] Singhal, M., \& Shukla, A. (2012). Implementation of location based services in Android using GPS and Web services. IJCSI International Journal of Computer Science Issues, 9(1), 237-242.

[25] Ghogare, S. D., Jadhav, S. P., Chadha, A. R., \& Patil, H. C. (2012). Location based authentication: A new approach towards providing security. International Journal of Scientific and Research Publications, 2(4), 2250-3153.

[26] Aithal, P. S., Shailashree, V. T., \& Kumar, P. M. (2015). Application of ABCD Analysis Model for Black Ocean Strategy.

[27] Aithal, P. S., Shailashree, V. T., \& Kumar, P. M. (2016). ABCD analysis of Stage Model in Higher Education.

$* * * * * * * * * *$ 